\section{Concurso de Monografias}

Até o dia 25 de abril a Secretaria de Modernização e Reforma Administrativa (Semor) do Ministério da Administração esiará recebendo os trabalhos para - Concurso Nacional de Monografias sobre a Reforma da Administraçâo Pública Federal, aberto desde o dia 2 de janeiro.

O concurso destina-se a brasileiros e estrangeiros que residam no Brasil no período de sua realizaçâo, excetuando-se os funcionários da Semor, e tem por objctivo estimular a realizaçāo de trabalhos sobre temas pertinentes à reforma da Administração Pública Federal, premiando o primejro colocado com Cz $\$ 10 \mathrm{mil} ;$ a segundo com Cz\$6 mil e, ainda, outros quatro trabalhos considerados pela Comissão Julgadora de interesse para publicaçâo, com Cz\$1 mil cada.

As monografias deverão tratar de aspectos práticos da implantação das políticas públicas, contribuindo para uma melhor compreensão da rcalidade $\mathrm{da}$ Administração Pública do Pais, subsidiando o desenvolvimento e a execução de medidas da Reforma Administrativa.

Os participantes poderão optar por aspectos gerais ou casos especificos, considerando a Admintsisaçāo Direra e Indireta, analisando funções, programas e/ou subprogramas de governo, tratando da execução de políticas setoriais ou, ainda, analisar a situação e atuação de empresas ou autarquias, face às politicas setoriais.

Embora os temas sejam livres, a coordenaçảo do concurso sugere alguns assuntos considerados de interesse, como "A Reforma Administrativa na Nova República - Estratégia e Ação";

"Adr" nistração Direta e Indireta: Conlradiçōes e

complementariedade"; "Obsıáculos e propostas de soluçōes para

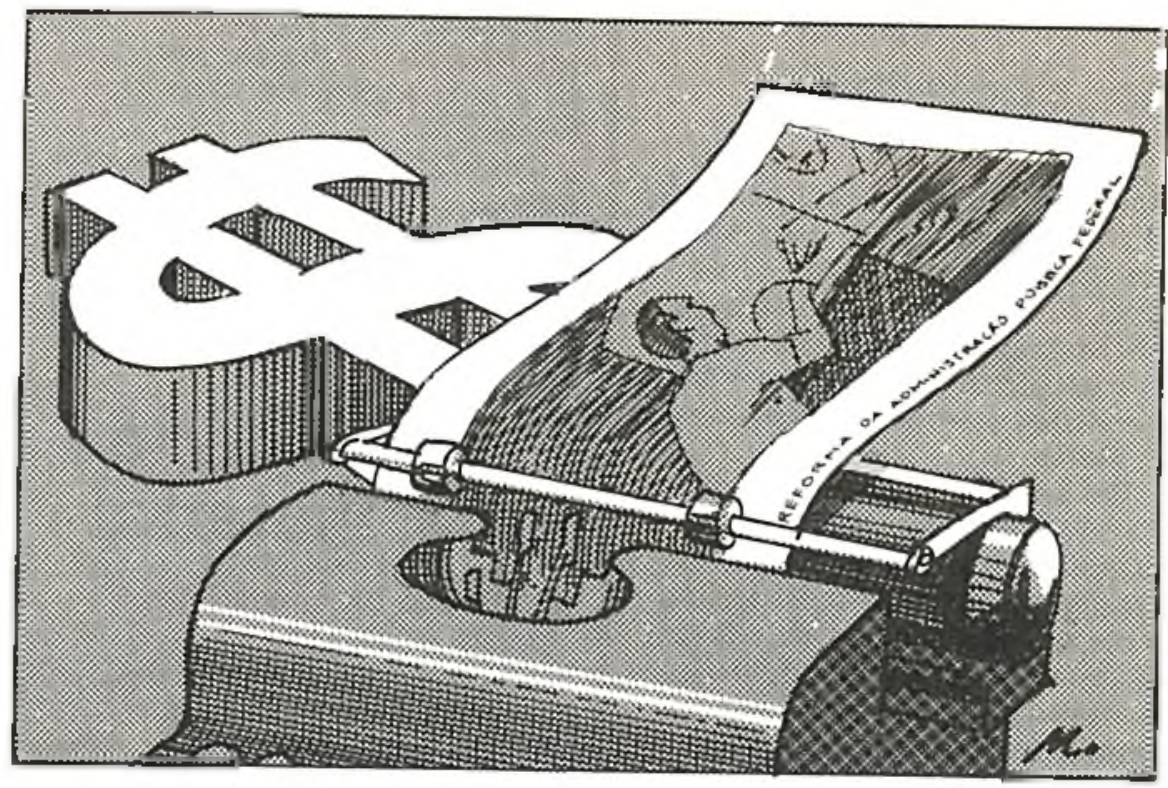

mudanças na Administraçāo Pública"; "Mecanismos para aprimorar a avaliação da eficácia e da eficiência das ações governamentais"; "Modernizaçāo das instituições para o

desenvolvimento sócio-econômico"; "A carreira do servidor e o Serviço Público"; "O sistema de Serviços Gcrais: sua contribuição para a eficácia da Administração Pública" e, "A função do controle na Administração Pública como instrumento gerencial".

As monografias deverão ser apresentadas em português, em três vias datilografadas em espaço duplo e, de preferência, não ultrapassando 75 páginas, excluidas as relativas à bibliografia e aos anexos. A idenrificaçâo será feila através do pseudônimo,

acompanhado de envelope lacrado contendo os scguinte dados pessoais do autor: nome, endereço residencial e profissional, data de nascimento, número do documento de identidade, CPF, formação acadêmica e experiência profissional. O envelope deverá vir identificado com o título do trabalho e o pseudônimo utilizado. Os concorrentes estrangeiros deverão incluir no envelope lacrado a prova de sua condiçâo de residente no País.

A Comissảo Julgadora se reserva o dirciro de nâo atribuir os prêmios se considerar que os trabalhos apresentados não encerram contribuição valiosa ao conhecimento dos temas propostos, e suas decisões serão irrevogáveis e definitivas, não cabendo recurso quanto à classificaçāo. Os critérios para scleção dos trabalhos são: adequação do texto ao tema escolhido, fundamentação metodológica e teórica das proposiçōes, relevância, atualidade e originalidade das proposiçōes, clareza e objetividade do texto.

A Semor publicará os trabalhos premiados, reservando-se ainda, quanto aos demais, o direiro de editá-los total ou parcialmente. Os títulos dos títulos inscritos co resultado final serāo publicados no Diário Oficial da Uniâo. A entrega dos prêmios se fará em data a ser fixada no mês de junho $e_{1}$ caso o premiado não resida ou trabalhe em Brasilia, fará jus à passagem de ida c volta para particjpar da solenidade de premiaçāo.

As monografias e o envelope lacrado de identificaçāo deverão ser enviados para: Concurso Nacional de Monografias sobre

Refoma da Adminisı ração Pública Federal. Secretaria de

Modernizaçāo e Reforma Administrativa - Semor - SAS - Quadra 6, Bl. "O", 40 andar CEP 70070 - Brasilia - DF 


\section{Gileno agora}

\section{na Secretaria}

O professor Gileno Fernandes Marcelino é o novo secretário-geral do Ministério da Administraçāo. Em sua posse, o ministro Aluízio Alves destacou a amizade pessoal e profissional que os une há quase 30 anos, desde os tempos em que o ministro governou o Rio Grande do Norte.

Em seu discurso, Gileno recordou lambém essa época, quando coordenou o processo de reforma administrativa do Estado. Sobre o atual processo de reforma da Administraçāo Federal, cle afirmou que o Brasil tem pago elevado preço político, social e econômico por ter tratado a questāo administrativa de maneira casuística e pouco séria, acrescentando que, por isso, é de fundamental importância a institucionalizaçāo do Ministério ou Secretaria de Administração Pública que, juntamente com a execução da Reforma da

Administraçāo, consolidarāo o planejamento administrativo no Governo Federal, antiga aspiraçāo dos administradores públicos do Pais.

\section{Pessoal cresce e custa mais}

No ano passado, o Governo gastou mais $37,4 \%$ em despesas com pessoal e encargos sociais na administraçâo direta; o número dc funcionários cresceu $10 \%$ e chegou aos 700 mil e, em dinheiro antigo, foram pagos Cr\$ 41 trilhōes e 835 bilhões, contra $C_{r} \$ 9$ trïlhōes e 410 bilhões em 1984.

As informaçōes sāo do Secretário-geral da Seplan, Andréa Sandro Calabi, segundo quem, só com pessoal, o Governo gastou $30,3 \%$ do orçamento do ano passado, que foi de $\operatorname{Cr} \$ 138,2$ trilhōes. Em 1984, a participaçāo dessa despesa no Orçamento foi de $26,3 \%$.

Calabi explicou que o aumento do número de funcionários públicos, em 1985, resultou do que chamou de "festival de contrataçōes" realizadas nos últimos seis meses do governo Figueiredo.

O Poder I egislativo gastou com pessoal Cr\$ 1,295 trilhão, mais $367 \%$ do que ano anterior; 0 Poder Judiciário gastou Cr 1,358, mais $436 \%$ a Poder Executivo, $\mathrm{Cr}$ 25 trilhōes e 359,9 bilhōes.

\section{Flexibilidade para material}

O Ministro da Administraçāo,

Aluizio Alves, vem

fazendo um levantamento das necessidades de compra de material permanente e nãopermanente nos ministérios, órgāos púhlicos e universidades. Tal levantamento será usado na elaboraçāo de um novo decreto proibitivo de compra de material. $O$ último decreto nesse sentido expirou no dia 31 de dezembro passado. O ministro lembra a necessidade de nova proibição, desta vez menos radical. $O$ decreto do ano passado nāo permitia a compra de qualquer tipo de matcrial, em face da urgência de evitar gastos excessivos no final do ano.

O novo decreto deverá adotar um critério seletivo. Material de laboratório c livros, por exemplo, não sofrerâo restrições, enquanto рата а compra de ar condicionado e de material de escritório será exigida autorizaçāo especial.

\section{Carros para freiar preços}

O ministro Aluizio Alves determinou a suspensão dos leilōes dos automóveis de representaçāo utilizados pcla administração direta. Motivo: quase I. 300 veículos passaram à disposiçāo da Sunab - Superintendência Nacional de Abastecimento, para auxiliar na fiscalização dos preços tabelados pelo Governo em todo o Pais.
Aluízio decidiu, ainda, que, em caso de necessidade, a Sunab poderá requisitar da administraçāo direta quantos funcionários forem precisos para auxiliar a

fiscalizaçâo, em qualquer cidade brasileira, com o custo correndo por conta dos órgāos de origem.

Enfatizou o Ministro que a fiscalização dos preços de mercado é, atualmente, a meta prioritária do Governo e nenhum esforço será poupado para alcancá-la.

\section{Senapro chega para agilizar}

No dia 17 de abril, o Ministro da Administraçāo, Aluízio Alves, inaugura oficialmente o Senapro - Serviço Nacional de Protocolo, destinado a agilizar o atendimento ao público e abrir caminho para a implantação da Reforma

Administrativa.

Criado no início do ano, o Senapro entrou em funcionamento em meados de fevereiro passado, atendendo aos interessados através do telefone 1515, para chamadas locais do Distrito Federal, ou pelo DDD 061-1515. Para obter a informação desejada, o interessado só precisa fornecer o número do protocolo, ou o seu nome e assunto, a resposta do Senapro inclui a localização do processo (qual a repartição), o último despacho proferido e o nome e ramal do funcionário dele encarregado.

Por enquanto, as informaçōes atingem apenas os processos $\mathrm{cm}$ tramilaçāo nos ministérios da Administraçâo e da Fazenda. Com sua expansâo, cobrirá todos os órgãos do Governo, pondo lim à verdadeira "via-crucis" tāo comum quando se pretende localizar um processo. Acabarāo também o famoso "jcitinho" e o recurso aos despachantes de balcão, porque, de 15 em 15 dias, o ministro receberá uma relação dos processos cm trânsito c, se um deles aparecer mais de duas vezes sem andamento, dererminará providências imediatas para agilização. 